\title{
O LIVRO E SUAS REPRESENTAÇÕES NOS CONTEXTOS ARTÍSTICOS CONTEMPORÂNEOS
}

\author{
THE BOOK AND ITS REPRESENTATIONS \\ IN CONTEMPORARY ARTISTIC CONTEXTS
}

\author{
Giulia Crippa* $^{*}$
}

\begin{abstract}
Resumo
Neste artigo, propomos o estudo de algumas representações visuais de livros e das leituras que artistas e gráficos convidam leitores e públicos a realizar. Para tanto, utilizamos uma metodologia oriunda da História Cultural, com a finalidade de desenhar uma topografia das interações entre o livro enquanto objeto e a ação da leitura no âmbito do imaginário social, através das permanências e das mudanças dessa interação nas representações selecionadas para o estudo. Nossa proposta visa, assim, descrever algumas imagens com base em uma proposta de paradigma conjectural como apresentado por Ginzburg (2004), questionando os exemplos enquanto Imagines Agentes de livros e leitores. O intuito é configurar as representações do imaginário acerca do livro e da leitura em um momento em que, diante das novas tecnologias de informação e comunicação, se discute seu futuro e o das novas relações de leitura proporcionadas por essas tecnologias. O prisma de observação das representações dos livros e da leitura oferece várias perspectivas: o livro como objeto físico ou como espaço mental; o livro evocado; o livro como guia de viagem, entre outros. Nosso estudo procura exemplificar e mapear alguns dos elementos que caracterizam essas representações, que as tornam objeto de interesse para oferecer elementos para uma história e uma sociologia do imaginário acerca dos livros e de seus leitores.
\end{abstract}

Palavras-chave: Livro. Representações. Imaginário. Arte.

\begin{abstract}
In this article we propose the study of some visual representations of books and of the reading artists and graphics invite readers and public to perform. To achieve that, we will apply a methodology rooted in Cultural History, aiming to design a topography of interactions between the book as an object e the act of reading present in social imaginary, through long lasting signs e changes in this interaction among representations selected for this study. This paper proposes a description of some representation based on the model of the so called conjectural paradigm, questioning the chosen examples because of their being Imagines Agentes of books and readers. The idea is to configurate the representations of social imaginary about books and reading in an era when, facing new technologies of information and communication, we debate their future and the future of the new relations we establish with reading, offered by these technologies. The prism through which we observed the representations of books and reading offers different perspectives: the book as a physical object or as a mental space; the evocated book; the book as a travel companion, among others. Our survey tries to exemplify and map some of the elements that turns these representations interesting, that made them object of interest, in order to offer elements for a history and a sociology of imaginary on books and readers.
\end{abstract}

Keywords: Book. Representation. Imaginary. Art.

\section{Introdução}

Propomos o estudo de algumas representações sociais do livro "imaginado", aqui proposto como um índice de um percurso de temas e valores que são mantidos e/ou transformados no

\footnotetext{
* Professora Associada do Dipartimento di Beni Culturali, Università di Bologna. Livre Docente em Ciência da Informação pela FFCLRP/USP. Doutora em História Social pela FFLCH/USP. Bacharel em Lettere Moderne pela Università di Bologna. E-mail: giulia.crippa2@unibo.it
} 
processo de secularização da Modernidade. O trabalho de Curtius (1996) abre as portas para o imaginário, a representação e o simbolismo do livro pela perspectiva da literatura, enquanto do ponto de vista iconográfico pode-se recorrer à perspectiva de Aby Warburg (2012) (e seus discípulos, entre os quais Panofsky, Gombrich, Saxl, Baxandall, Ginzburg). Para essa escola, o poder memorial das imagens é central e provoca uma renovação epistemológica no campo dos estudos iconográficos, que é reconfigurado como "antropologia da visão", na qual se reconhece a autonomia da linguagem da arte (DIDI-HUBERMAN, 2013), tentando, no entanto, ver os componentes que permitem identificar modelos emblemáticos para os quais as razões de sua aparição são investigadas e suas funções são estudadas como meios de transmissão de valores socialmente construídos na esfera do imaginário.

As histórias começam nas páginas dos livros que ocupam as estantes das livrarias e das bibliotecas, cujas narrativas prosseguem, como veremos, na tradução de alguns artistas do passado e do presente. Grandes autores sempre tiveram uma influência notável no desenvolvimento das poéticas, tornando-se, ao longo do tempo, fontes de inspiração, não somente para outros escritores, mas também para os artistas, sejam eles do passado, bem como contemporâneos.

O Narrador é o título de um bem conhecido ensaio de Walter Benjamin (1962), que trata da prosa de Nikolai Leskov. As reflexões de Benjamin a respeito da qualidade e do poder dos grandes narradores são bastante relevantes no âmbito da teoria literária, mas se apresentam como valiosos também no campo da interpretação que os artistas elaboram da literatura. Mesmo Benjamin expressando sua preocupação sobre o fim da arte da grande narrativa, ele escreve, com grande visão: "Sugestões tecidas na fábrica da vida real são sabedoria. A arte da narração está chegando ao seu fim porque o lado épico da verdade, a sabedoria, está se esgotando" (BENJAMIN, 1962, p.182). Benjamin marca um ponto válido, em termos de narrativas orais, mas claramente a arte da narrativa escrita não estava se esgotando, assim como a arte da narrativa reelaborada pela arte aparenta, por outro lado, florescer. Benjamin descreve as qualidades inerentes à narrativa, enfatizando tanto o papel do narrador, bem como o do público, papéis que poderíamos estender aos do artista e do público da arte.

A narração é sempre a arte de repetir as histórias, e essa arte se perde quando as histó-
rias não são mais lembradas. Se perde quando não há mais a tecelagem e o urdido em
ação, enquanto são ouvidas. Quanto mais o público esquece de si, quanto mais profun-
damente aquilo que ouve se imprime em sua memória. Quando o ritmo do trabalho
o cativa, escuta as histórias de maneira tal que o dom de contar de novo aparenta ser,
para ele, sem esforço. Essa, portanto, é a natureza da rede em que o dom da narração
se embala. É isso que hoje está se esgarçando, depois de ter sido tecido por milhares
de anos, no ambiente da forma mais antiga de artesanato (BENJAMIN, 1962, p. 185).

As pinturas, instalações, esculturas, fotografias, desenhos que queremos apresentar e estudar não são interpretações miméticas das obras literárias, bem como não necessariamente as ilustram. Porém são profundamente inspiradas, de maneira clara, à literatura e à poesia, 
portanto à leitura. Como para todas as histórias, a narrativa é complexa e entrelaçada, rica em metáforas e simbolismos, compreendendo também viagens pessoais, ou, ainda, realizadas de maneira mais "teórica". De qualquer maneira, todas as obras contam histórias a partir do fio condutor de histórias já existentes.

Trata-se, portanto, de artistas que se tornam eles mesmos narradores, com a habilidade de enredar as narrativas existentes pelos trilhos da arte, revelando a dívida com as palavras e, ao mesmo tempo, ilustrando texto e linguagem de maneira separada das mesmas.

Claro, o jogo entre texto e imagem não é novidade, mas as obras em análise, como veremos, revelam uma ligação bastante específica com a literatura: livros reais, livros imaginários, réplicas de livros, coleções de livros, páginas de livros, partes de livros, imagens de livros, instalações de livros, se tornam quase uma materialização do universo borgesiano.

Utilizaremos uma metodologia oriunda da História Cultural, com a finalidade de desenhar uma topografia das interações entre o livro enquanto objeto e a ação da leitura no âmbito do imaginário social, através das permanências e das mudanças dessa interação em obras produzidas pelas representações escolhidas. O intuito é configurar a representação do imaginário acerca do tema em um momento em que, diante das novas tecnologias de informação e comunicação, se discute seu futuro e o das novas relações de leitura proporcionadas por essas tecnologias, como mostram Chartier (1999), Murray (2003) e Santaella (2004), entre outros. Entre as representações processadas dentro de um universo mais amplo pesquisado, selecionamos algumas que permitem ser usadas como Imagines Agentes ${ }^{1}$.

O olhar de escolas históricas, voltadas para uma pesquisa indiciária, como propõe Carlo Ginzburg (2004), leva a perspectivas interessantes em suas abordagens inéditas de análise dos sistemas de representação de livros, leituras e leitores. Em relação à representação de livros e leitores na literatura, não faltam estudos e monografias. Na segunda metade do século XX, temáticas ligadas à produção e circulação de livros e suas representações como produtos da ordem do imaginário têm convergido as pesquisas de profissionais ligados às Ciências Humanas e Sociais de maneira consistente, reunindo capitais culturais diferentes na reflexão sobre o tema da representação do livro. Consequentemente, do imaginário e dos quadros sociais da leitura (CURTIUS, 1996) para uma compilação bibliográfica extensa sobre a simbologia do livro na literatura ocidental desde antiguidade até o século XIX; Cavallo e Chartier (2002) e Chartier (2001) abordam vários aspectos das práticas de leituras e de suas representações.

A representação de livros e de leituras, tanto em sua aparição iconográfica como no desenvolvimento textual, deveria "permitir reavaliar os discursos que objetivam regulamentá-la, dizer sua norma ou prescrevê-la, como aqueles que pretendem construir uma descrição objetiva, histórica ou sociológica, das práticas de leitura" (FRAISSE; POMPOUGNAC; POULAIN, 1997, p. 8).

$1 \mathrm{O}$ termo se enraíza na retórica. Por imagines agentes, entende-se figuras de linguagem capazes de trazer de volta à memória do orador todas as partes do discurso necessárias para a eficácia da oração. 
O prisma de observação das representações dos livros e da leitura oferece várias perspectivas: o livro como objeto físico ou como espaço mental; o livro evocado; o livro como guia de viagem, entre outros. Nosso estudo pergunta quais são as características dessas representações, que as tornam objeto de interesse para integrar uma história do conhecimento e de seus atores.

A força memorativa de determinadas imagens está no centro das pesquisas de Aby Warburg (2012), que provocou uma renovação epistemológica no campo da história da arte, que seguiu nos estudos realizados pelos discípulos Panofsky (1975), Gombrich (2003), Saxl (2005), Baxandall (2006) e Ginzburg (2004). A mudança de enfoque sobre os fenômenos artísticos se atrela a uma "antropologia da visão", considerada por Warburg a faculdade primeira de apreensão da mente humana. A História Cultural fundamentada nesta antropologia da visão entende a autonomia da linguagem da arte, buscando, assim, caracterizar as partes dessa linguagem. Dessa forma, é possível identificar alguns aspectos que cabe ao pesquisador estudar, sempre lembrando que o ato da descrição parcialmente interpretativa "é menos uma representação do quadro, ou mesmo uma representação do que se vê no quadro, do que uma representação do que pensamos ter visto nele" (BAXANDALL, 2006). As representações de livros, leitores e leituras, constituem no tempo um conjunto de representações ainda a ser ordenado, para as quais buscamos as razões do aparecimento, de sua configuração e dos olhares aos quais se oferecem, propondo veredas pelas suas funções sociais na transmissão cultural.

A expressão de narrativas visuais, anteriores à escrita, existe desde o paleolítico (como no caso das grutas de Lascaux) e, até hoje, as imagens se sobrepõem e se substituem às palavras; por exemplo, para favorecer a compreensão de narrativas sobre feitos civis ou religiosos, como acontecia no Egito e em Roma, ou na Idade Média e Moderna, enquanto se observa que a fotografia não mudou essa função ideológica da narrativa visual, mas sim suas modalidades e efeitos sobre os públicos.

Na produção artística e gráfica, é interessante, para além da narração pessoal, observar aquilo que acontece quando as manifestações visuais criam obras baseadas em narrativas escritas de natureza poética ou ficcional já familiares ao público. Escreve Jacques Rancière (2007, n.p):

\footnotetext{
Os artistas, como os pesquisadores, constroem o palco onde a manifestação e o efeito de sua competência se torna dúvida, enquanto emolduram a história de uma nova aventura em um novo idioma. O efeito do idioma não pode ser antecipado. Congrega os espectadores ativos enquanto intérpretes, que procuram inventar sua própria tradução para se apropriar da história, construindo, assim, sua própria história. Uma comunidade emancipada é, de fato, uma comunidade de narradores e tradutores. Estou consciente do que isso possa aparecer: palavras, somente palavras. Mas não o considero um insulto.
}

Cada narrativa que conta novamente uma história constrói um palco no qual não somente repagina/emoldura a história em uma nova língua, mas recria e reencena histórias já contadas. Aos públicos, por outro lado, se pede para serem intérpretes ativos e novos narradores. 


\section{Algumas reflexões sobre "ilustrar" um livro}

É lugar comum afirmar que um texto e sua ilustração, como forma de representação, são complementares. Se, de um lado, isso se aplica facilmente na leitura e observação de livros infantis, didáticos e a alguma representação de obras particularmente imagética, como é o caso das ilustrações de Gustave Doré para os três cantos da Divina Commedia, por outro, é necessário recorrer aos estudos semióticos para esclarecer essa relação. Michel Melot (1984) afirma que “a imagem não é mais um apêndice, decoração ou redundância do texto. É simplesmente uma técnica diferente de estruturar o conhecimento" (p. II). Mais à frente, alega que:

combinação de imagens e escrita [...] introduz no sistema de signos uma incoerência fortificante e frutífera, pois confronta o leitor com sua própria verdade. O signo pode ser mais ou menos próximo ou distante de seu significado, que pode ser natural ou arbitrário, sem por isso afetar sua natureza ou valor enquanto signo - tudo isso mostrando claramente que a relação do signo com seu conteúdo não é certificada na ordem das coisas em si (MELOT, 1984, p. 13).

O autor elabora, nesse rumo, a teoria dos signos de Foucault que escreve "o signo para de ser uma imagem do mundo, e para de ser vinculado ao que distingue através dos vínculos sólidos e secretos da semelhança ou da afinidade" (FOUCAULT, 1988, p. 73). A observação das ilustrações de textos revela uma função crítica dos ilustradores, enquanto intérpretes das narrativas, com o poder de destacá-las ou distorcê-las. As representações, por exemplo, podem enfatizar ou somar informações até ausentes no texto, a ponto de oferecer interpretações de certos aspectos da narrativa, revelando implicações das quais nem o autor do texto, às vezes, é consciente. Em certa medida, a ilustração se torna a leitura e interpretação do texto do ilustrador, somando elementos estéticos, sociais, históricos. As ilustrações dos textos, porém, mantém uma relação que força os leitores a cotejar as duas representações, mesmo mantendo sua independência. Um dos elementos que caracteriza as ilustrações é a seleção do momento/ ação a ser representado. Melot afirma que o ilustrador deve possuir "a arte de escolher o momento crítico" (MELOT, 1984, p. 7, grifo do autor). Uma sequência de ilustrações, fragmentadas pelo texto, se revelam pausas significativas no continuum da narrativa.

Apesar de cada ilustração singularmente se apresentar como estática, sua sequência constitui também um fluxo narrativo, ou seja, o efeito cumulativo das ilustrações implica um movimento no tempo e no espaço. As escolhas individuais dos ilustradores sobre a composição, as personagens, as imagens, os símbolos, bem como a organização de sua seleção em relação ao texto e a escolha de manter determinados assuntos, determinam o desenvolvimento da narrativa visual em seu entrelaçamento com o texto. Melot questiona, porém, como o ilustrador é mais que um mero colaborador do autor, contribuindo de maneira independente para o texto: 
Enquanto a ficção ganhava terreno [...] imagens baseadas nela cresceram independentemente. A ilustração alcançou um valor específico, pois somava ao texto algo que este não podia mostrar. Se concentrava em um ponto particular, sobre o qual se concentrava e ampliava. Seu poder de suspender a narrativa em um momento singular do enredo contribuía a fornecer um toque de maravilhoso. (MELOT, 1984 p. 110-111).

O ilustrador, nesse sentido, busca ampliar o texto através de sua perspectiva de artista intérprete e tradutor de outra narrativa. Na medida em que as escolhas dos ilustradores refletem suas orientações pessoais, bem como suas reações às mudanças na percepção das narrativas por parte da crítica literária, dos eventos políticos das convenções estéticas e culturais ao longo do tempo, as narrativas visuais mudam. Em todo caso, essas narrativas visuais providenciam subtextos para a interpretação dos leitores e dos públicos. Não trataremos, portanto, de livros de artistas strictu senso, pois em todos os casos as obras se espelham em narrativas já escritas, reformuladas em uma outra linguagem não textual.

É necessário destacar uma diferença fundamental entre a ilustração, que é parte integral de um texto escrito, e a pintura ou a escultura. Essas últimas podem se inspirar, traduzir ou construir uma nova narrativa, mas se colocam em um lugar e em um tempo de leitura diferente do livro, na medida em que interagem com um outro ambiente, que é o do museu, da galeria ou de um ambiente externo. O impacto com o espaço em que se encontra a representação artística pode reduzir ou até apagar a relação colocada entre a narrativa original e a obra de arte.

Assim, o diálogo estabelecido pela obra de arte autônoma pode se estabelecer com o espectador, mas não necessariamente o espectador dialoga também com a narrativa do texto escrito. Isso, porém, reforça nossa ideia da construção de uma nova versão que encena a multiplicidade de leituras possíveis. Exemplo disso pode ser encontrado na instalação "A onda do mar", realizada entre 1991 e 1997, em que o autor, Cildo Meirelles, pede para que sejam colocados no chão dúzias de volumes impressos. Seguindo suas instruções, trata-se de livros que contêm unicamente fotografias de água para compor uma imagem poética do mar. Encontramos, aqui, o uso de livros enquanto configuração material de uma "intenção" visual do mar, na medida em que a palavra água é repetida, em línguas diferentes, por uma série de alto-falantes. Cada livro é aberto em uma determinada página, mas sua função para a leitura é negada, enquanto sua acumulação, como tijolos, forma uma imagem maior².

\section{Entre Melville, Borges e Joyce: as narrativas dos artistas}

Conforme Schultz (1995), o primeiro pintor que se inspirou livremente no romance Moby Dick foi Karl Knaths em 1935, pintando “Moby Dick”. A escolha do artista é de representar uma cópia do próprio livro, colocando-o entre outros objetos, em uma espécie de natureza morta

2 Disponível em: http://artelatina2009.blogspot.com/2009/08/brasil-8_25.html Acesso em: 18 mar. 2020. 
que compreende uma caixa com um navio, um busto em estilo cubista e um globo dourado. $\mathrm{O}$ enfoque de Knath nas formas (o livro, o navio, o busto) sugere um interesse compartilhado com Melville nos diferentes e, às vezes, conflitantes papéis do artista, do leitor, do autor e do observador na interpretação da narrativa. Na pintura, Moby Dick, o livro, é colocado de maneira quase metafísica, emblema de ideais de vida americanos e, ao mesmo tempo, desafio para qualquer tentativa de agarrar o livro materialmente, metáfora da impossibilidade de alcançar esses ideais. $\mathrm{O}$ artista realizou outras representações do livro, na tentativa de interpretar visualmente o texto. De 1966, é o óleo "Ishmael", e de 1970, "Moby Dick, the Third Day". Nessas obras, Knaths se volta para uma pintura mais tradicional, apresentando um retrato do narrador da história e a representação da cena do confronto final entre o Pequod e a baleia branca. Se a pintura de 1935 apresentava tonalidades pouco intensas, as obras mais recentes utilizam uma paleta de cores bem mais intensa, próxima das técnicas das histórias em quadrinhos. O rosto de Ismael é fragmentado, com tonalidades de verde, laranja, rosa e azul, sugerindo a complexidade da experiência vivida pelo narrador. Um olho se fixa no observador, enquanto o outro, na sombra, parece se voltar para dentro. $O$ fundo é dividido entre verde e púrpura, reforçando essa proposta de leitura de um mundo dividido. Na última pintura, encontra-se, no canto direito embaixo, uma retomada do busto de 1935, em uma versão cubista, com um perfil masculino realizado com pinceladas de azul, púrpura e escarlate. Não se pode dizer se é a imagem de Achab ou de Ismael, mas seu destaque contra o fundo leva o espectador a testemunhar a devastação do Pequod ao lado dele e a adentrar a história com suas próprias reflexões.

Observamos uma instalação realizada por Ernesto Neto em 2010. Ernesto Neto é um importante artista multimídia carioca, nascido em 1964, que procura criar, em suas instalações, espaços de intercâmbio social, solicitando ao espectador a superação da experiência meramente visual, através da solicitação de outros sentidos. Entrar nessa obra de Ernesto Neto significa iniciar uma viagem pessoal da imaginação, seguindo as veredas do mundo filosófico e metafísico de Borges, representadas perlo conto As ruínas circulares. Trata-se da instalação "CírculoPrototemplo"3, narração visual do conto Borgesiano, composto por um enredo de camadas múltiplas em que a narrativa explora as relações entre a ficção e a experiência do real, que trata da viagem de um mago que adentra umas ruínas circulares com o objetivo de gerar um filho vivo, com um verdadeiro coração, através unicamente de seus sonhos e fantasias. Depois de quatorze noites dormindo, ele sonha, finalmente, com um coração perfeito e pulsante, que acredita tratar-se do primeiro passo para alcançar seu objetivo. A história centraliza o pensamento de Borges segundo o qual cada um percebe a realidade sem podê-la distinguir de uma ilusão, de uma criação, portanto, da imaginação. Através da história, estabelece-se uma linha sutil entre imaginação e realidade. Assim, no final, o mago percebe que o filho imaginado existe

3 Disponível em: https://noticias.bol.uol.com.br/ultimas-noticias/entretenimento/2010/06/16/ernesto-neto-transforma-galeria-hayward-com-suas-instalacoes.htm Acesso em: 05 out. 2019. 
unicamente em seus sonhos. Pior ainda, descobre que ele também não passa de um fragmento de imaginação de outra pessoa.

O trecho do conto a partir do qual Ernesto Neto elabora sua narrativa visual (e sensorial) é o seguinte:

Sonhou que era quente, segredo, mais ou menos do tamanho de um punho fechado [...]. Durante as catorze noites sonhou-o com meticuloso amor. Cada noite o percebia com maior clareza. Não encostou nele; permitiu-se unicamente de testemunhá-lo, de observá-lo e, ocasionalmente, de arrumá-lo com um olhar. O percebeu e o vivenciou de cada ângulo e distância. Na décima-quarta noite tocou de leve a artéria pulmonar com o dedo indicador, depois o coração inteiro, por dentro e por fora (BORGES, 1999, p. 25).

Ernesto Neto construiu uma estrutura vermelha com o formato de um coração que, com a colocação em seu interior de um tambor, bate conforme o ritmo fornecido pelo público através do tambor. A estrutura é lúdica e busca estimular a interação tanto dos adultos como das crianças. Podemos observar os pormenores da estrutura completa: nos detalhes das superfícies coloridas e brilhantes e do ambiente criado no interior desse coração se encontram a habilidade do artistaartesão na elaboração da narrativa através da aproximação sensorial dos materiais, ambientes e sons. São as interações dos indivíduos com a vontade de dar vida a esse coração que centralizam o interesse do artista, que procura estimular o ato criativo, da imaginação. A instalação oferece, assim, um espaço no interior do coração vermelho, onde o público pode sentar, conversar, tocar o tambor, isto é, torná-lo autônomo, com vida própria. A ideia de viagem individual está presente nas suas obras, e o público se torna participante ativo da instalação, adentrando seu interior e sentindo-se envolvido pelas cores, formas, cheiros e sons. A obra não é somente um convite à experiência sensorial, mas ao âmago do conto. Como em todos os trabalhos de Neto, a obra pode ser tocada, percorrida, atravessada. O espectador é estimulado a se concentrar em sua própria percepção da obra e interagir com ela e com o ambiente em volta. Retoma, então, a teoria de Rancière para o qual o público deve tornar-se intérprete ativo no exato momento em que entra em relação com a representação de maneira física, emocional e intelectual.

Marilá Dardot (1973) é uma artista para a qual a literatura é a fonte para as obras. Em 1999, a partir do conto O livro de areia ${ }^{4}$ de Borges, realiza um livro feito de espelhos, com o mesmo nome, condensando questões que permeiam sua produção, isto é, a literatura e a participação do espectador. O conceito de seu livro de espelhos é, justamente, sua relação com o livro paradoxal descrito por Borges, construído na base da ideia de um livro de páginas infinitas. Como é típico de Borges, o conto origina uma teia intricada de segredos, tesouros, charadas e sonhos entrelaçados na narrativa surreal. Mais do que criar uma interpretação direta do conto de Borges, Dardot oferece referências a Heráclito e à sua noção de panta rei, tudo passa e não

4 Disponível em: https://mariladardot.com/artwork/o-livro-de-areia-the-book-of-sand/ Acesso em: 05 out. 2019. 
pode voltar. Essa segunda referência diz respeito ao fato de que um leitor, em uma segunda leitura, nunca encontrará os mesmos significados em suas páginas, mesmo o livro sendo igual. No final, Dardot não somente cria uma obra de arte, mas um livro real que funciona como um infinito contínuo em que arte, literatura, quotidiano e filosofia se tornam inextricáveis.

Suas obras se apresentam mais como diálogo que como adaptação, colaboração. Para ela ambos, artista e autor, colaboram, na medida em que se estabelece o diálogo com aquela obra, narrada através da leitura que dela a artista elabora. Não apenas a literatura faz parte do seu trabalho, mas o livro como um objeto também está muito presente.

Livros comprados em sebo, que trazem a história do objeto, as marcas de leitura, inspiraram o trabalho "Sebo", feito em parceira com o artista Fábio Morais. O livro aparece no seu trabalho também como um objeto escultórico, como em "Terceira margem" (2007) e "Volta ao dia em 80 mundos" (2013) e "O livro das mil e uma noites" (2014). Depois de uma viagem para a Eslováquia, que tem uma grande tradição de desenho de animação, percebeu que o design dos livros traduzia uma cultura e, a partir dessa pesquisa, produziu a série de representações "Minha Biblioteca" (2014-2018).

Elida Tessler (1961) realiza, em 2010, a instalação "Dubling"5 (2010), concebida a partir de 4311 gerúndios retirados do romance Ulisses de James Joyce, reunindo 4311 garrafas, 4311 rolhas com palavras impressas e 4311 cartões-postais. Trata-se de uma verdadeira homenagem bibliófila à obra principal de James Joyce. O relato da artista sobre a criação é anedótico, mas é parte da própria obra. Durante uma viagem para Dublin, Tessler visitou os lugares retratados no romance joyciano. Em seguida, durante outra viagem, dessa vez à França, enquanto sentava em um café, pediu uma garrafa de vinho, na rolha da qual havia impressa a palavra esperança. Enquanto o garçom abria a garrafa, citou Joyce: "homem e mulher, amor, o que é? Uma rolha em uma garrafa". A artista afirma ter se inspirado nessa experiência incomum ${ }^{6} \mathrm{e}$, voltando ao Brasil, começou a ler, sentada em um café de Porto Alegre, todos os dias, o Ulisses em português e em inglês seis vezes, marcando todos os verbos que encontrava. Tornou todos os tempos verbais gerúndios, gravando-os em rolhas, que colocou nas 4311 garrafas vazias. Ao lado delas, colocou uma grande gaveta de madeira, parecida com um ficheiro, contendo 4311 postais com fotos do rio Liffey, que atravessa Dublin, acompanhadas pelos verbos no gerúndio.

Na obra "Palavras-chave" composta por nove claviculários em metal - fixados à parede e contendo chaves com palavras gravadas - todas as palavras são retiradas de obras literárias, selecionadas a partir de critérios pré-estabelecidos pela artista. Com esse trabalho, a artista materializa a expressão "palavras-chave", condensando palavra, imagem e objeto. Os títulos de cada claviculário são inscritos em plaquinhas metálicas agregadas às caixas.

5 Disponível em: http://elidatessler.com/dubling/IMG09.htm Acesso em: 05 out. 2019.

6 Disponível em: http://www.elidatessler.com/textos_pdf/textos_criticos_1/In\%20Transition.pdf Acesso em: 20 jun. 2019. 
Seus trabalhos são sempre construídos com palavras, linguagens, literatura, livros, são inspirados pelos autores do cânone ocidental (Proust, Joyce, Eliot) e brasileiros (Guimarães Rosa), dos quais traduz, transcreve, escreve e reescreve as parole chave em objetos quotidianos, como chaves, lençóis,

Para concluir essa pequena galeria de artistas leitores que propõem leituras aos espectadores, gostaríamos de falar de dois artistas, Alfredo Jaar e Marisa Bonilla, ambos chilenos, que também se envolveram na produção de instalações ligadas a livros e leituras. Uma das instalações é uma sala nas cores preta e vermelha bastante ampla, onde se encontram centenas de livros para ler. Não se trata de uma livraria ou de uma biblioteca, mas da obra/instalação "Marx Lounge", verdadeira intervenção física e teórica que requer uma participação ativa dos espectadores para apreciação da obra. Se trata de um work-in-progress, na medida que, conforme é exibida, a instalação muda para se adaptar ao lugar e ao público. $\mathrm{O}$ que se mantém são as paredes vermelho quente, a iluminação estudada para otimizar a leitura e a presença de sofás confortáveis. Aproximadamente, o espaço contém 1.500 tascáveis ordenadamente dispostos em cima de uma mesa, com uma seleção de assuntos amplamente relacionados com o pensamento marxista, incluindo assuntos de economia, filosofia, história, psicanálise e, principalmente, política. Um dos aspectos relevantes do trabalho é que, para ler tudo, demoraria vários anos: "Marx Lounge" se propõe, assim, como antídoto à velocidade da sociedade em que vivemos, onde, para muitas pessoas, aparenta ter pouco ou nenhum tempo para a leitura.

Uma das habilidades de Jaar consiste na capacidade de convergir mensagens políticas em trabalhos que são tanto visualmente cativantes como conceitualmente significativos. A gigantesca mesa central, cobertas de livros em formatos e cores diferentes, é uma instalação em si, enquanto as paredes vermelhas, as plantas nos vasos e as luzes contribuem para gerar um ambiente perfeito para a reflexão intelectual. Claramente, cada visitante escolherá livros diferentes, conforme seu interesse e perspectiva particular. $\mathrm{Na}$ verdade, a leitura dessa obra oferece muitas possibilidades, mas o que permanece é que não importa o que queremos entender da instalação, cada página daqueles livros é um lembrete do valor do conhecimento e do trabalho intelectual. "El Capital/Manuscrito Siniestro" (2008) foi realizada por Milena Bonilla inspirando-se diretamente em um dos livros da "Marx Lounge", mais exatamente o Capital de Marx, em uma edição colombiana, mas, ainda assim, o livro de Bonilla é bastante diferente de qualquer livro presente na instalação de Jaar. De fato, Bonilla resolveu reescrever, com a mão esquerda, palavra por palavra, transformando o livro no "Manuscrito siniestro" 8 do título, com toda a ambiguidade presente no termo, que significa tanto escrito com a mão esquerda, bem como portador de um significado sinistro, na medida em que se torna ilegível.

Para realizar esse projeto, Bonilla criou duas versões do livro, sendo a segunda uma versão "pirata". Ambas as versões apresentam elementos a serem destacados: o manuscrito, pelo

\footnotetext{
7 Disponível em: https://www.biennial.com/2010/exhibition/artists/alfredo-jaar Acesso em: 05 out. 2019.

8 Disponível em: https://www.pinterest.it/pin/324188873155461870/ Acesso em: 05 out. 2019.
} 
absurdo de criar esse estranho objeto encadernado luxuosamente, enquanto a versão "pirata" apresenta qualidades de uma produção de massa, como um livro de bolso barato, acessível a todos. A ironia é que o texto, na grafia ilegível da artista, é incompreensível a todos. O trabalho não apresenta, portanto, uma homenagem ao livro de Marx, mas uma crítica às esquerdas e às suas contradições. Bonilla não somente reescreve um texto já existente, como também o desconstrói, tornando-o ilegível. Trabalhar com uma obra tão amplamente conhecida, pelo menos como título de referência, permite à artista a liberdade de transformar as palavras originais em algo incompreensível, pois o texto original está colocado como referência, através do título. Simbolicamente, a artista reescreveu com uma mão só Marx, isto é: reescreveu a história de maneira provocativa, desconstruindo vários mitos marxistas.

O exame das influências cruzadas entre objeto, imagem, texto e representação se apresentam como particularmente relevantes no manuscrito de "El Capital/Manuscrito Siniestro", realizado por Milena Bonilla, que se torna uma crítica ao endeusamento de Marx enquanto religião política do livro. Além disso, sua obra contradiz a ideia de livro como meio de comunicação baseado e criado pela impressão.

\section{Leituras recicladas}

A Eloisa Cartonera é uma cooperativa criada por autores argentinos e formada por dez sócios que, desde 2003, produz livros artesanais. O miolo dos livros é realizado com uma impressora caseira na sede da editora, a poucos passos do estádio La Bombonera ${ }^{9}$, enquanto as capas são confeccionadas em papelão comprado diretamente dos "cartoneros" argentinos - "profissão" que surgiu com a explosão do desemprego na crise de 2001 e que equivale aos catadores de papel brasileiros.

Segundo o Movimento Nacional de Trabalhadores Cartoneros e Recicladores, em Buenos Aires e arredores cerca de 100 mil pessoas vivem recolhendo papel, sendo que $98 \%$ deles não fazem parte de nenhuma associação ou cooperativa. Na editora, eles recebem 0,25 centavos de peso por caixa (o mercado paga 0,45 centavos pelo quilo). Ao som de uma boa cumbia, essas caixas viram capas, desenhadas e pintadas com temperas coloridas por jovens, filhos dos cartoneros. Cada livro é único e vendido por 5 pesos na própria editora, em feiras e em livrarias. As edições não passam de mil unidades e, para algumas pessoas, já viraram peças de coleção.

O catálogo é de primeira qualidade e tem somente autores latino-americanos. Ricardo Piglia, Alan Pauls, Mario Bellatin e César Aira. O último conto de Tomás Eloy Martínez só pode ser encontrado nessa edição. São quase 150 títulos, inclusive brasileiros (com a presença, no catálogo, de Haroldo de Campos, Manoel de Barros, Jorge Mautner, Glauco Mattoso e Wally Salomão).

9 Disponível em: https://en.wikipedia.org/wiki/Elo\%C3\%ADsa_Cartonera\#/media/File:Libros_de_Elo\%C3\%ADsa_Cartonera_2.jpg Acesso em: 05 out. 2019. 
A Eloisa Cartonera foi criada por Washington Cucurto (um dos heterônimos do escritor Santiago Veja) e pelo artista plástico Javier Barilaro (responsável pelos projetos gráficos), e a iniciativa deu tão certo que serviu de modelo para uma "rede cartonera". A partir da Eloísa nasceram pelo menos 15 editoras-irmãs, entre elas Yerba Mala Cartonera (na Bolívia), Sarita Cartonera (Peru), Lupita Cartonera (México), Animita Cartonera (Chile) e Dulcinéia Catadora (Brasil).

Os traços em comum das editoras se encontram no fato delas estarem situadas em periferias, desenvolvendo uma economia informal de subsistência, através de um trabalho artesanal realizado de forma coletiva, imprimindo tiragens limitadas e buscando sempre novos autores e leitores.

\section{Considerações finais}

Nossa contribuição apresentou obras que utilizam uma estrutura narrativa e, ao mesmo tempo, discutem, desconstroem ou até subvertem as próprias convenções narrativas. Os artistas apresentados são portadores de poéticas diferentes, e seus trabalhos compreendem pinturas e instalações, destacando que, como elemento comum, centralizam o livro e suas leituras, através da elaboração de novos contos. Esses narram, de fato, histórias já existentes de maneira inesperada, discutindo os próprios mecanismos da narrativa.

Por sua vez, a narrativa, fortemente enraizada na história literária, no teatro e na arte, se transforma. Representar a "realidade" e contar histórias (que são duas das principais funções que atravessam a história das manifestações artísticas) se deslocam rumo a uma finalidade mais rica e tecnológica, tanto morfologicamente como metodologicamente. O termo "narrativa", mutuado da teoria pós-estruturalista, é bastante utilizado como lugar-comum no âmbito da arte, referindose, porém, a determinados sentidos, valores e molduras ideológicos mais que as narrativas propriamente ditas como articuladoras das obras. A recusa contemporânea de narrar histórias na arte contemporânea decorre do cepticismo na possibilidade de comunicar a experiência diante da complexidade atual, em que a fratura entre arte, literatura e vida, bem como entre o "real" e o virtual, aumentou criticamente na época da artificialidade. Benjamin já anunciara isso no Narrador:

Em todo caso, o narrador é um homem que pode oferecer conselhos aos seus leitores. Mas se hoje "ter conselhos" começa a soar fora da moda, isso se deve ao fato de a comunicação da experiência ter se reduzido. Como consequência, não temos conselhos nem para nós mesmos, nem para os outros. Afinal, conselhos são menos uma resposta a uma pergunta do que uma proposta para continuarmos uma história que se desdobra [...] a arte da narração está chegando ao fim, porque o lado épico da verdade, a sabedoria, está ressecando. (BENJAMIN, 1962, p. 194).

Para Benjamin (1962), a sabedoria é constituída por "conselhos entrelaçados no tecido da vida real" (p. 194). Na sua visão, o primeiro sintoma do declínio da narrativa foi o nascimento do romance, no começo da Modernidade, com sua separação da vida: os romancistas se isolam, 
perdendo o contato direto e a comunicação viva com o público ouvinte que a literatura oral envolvia. A desconstrução da representação e das narrativas na arte contemporânea criou, por outro lado, novas abordagens que, paradoxalmente, nessa revisão incrementaram suas práticas. Nesse sentido, ponto crucial das novas narrativas tem sido seu caráter polissêmico, solo fértil para as pesquisas artísticas, como pode ser observado nas instalações de Marilia Dardot acerca dos textos literários.

Os artistas selecionados tratam de narrativa e literatura, mas também do livro. Como afirma Benjamin, "Aquilo que distingue o romance da história é sua dependência essencial do livro" (BENJAMIN, 1962, p. 197). Essa submissão ao livro como intermediário afastouse da literatura oral coletiva, imediata, da comunicação ao vivo, entre o narrador e o público, beneficiando a distância, o consumo individual e a preservação de um único texto.

Nossos artistas refletem o livro como entidade, entrelaçando suas componentes materiais e intelectuais, de acordo ou dialeticamente com os usos costumeiros que dele fazemos. São artistas que lidam com o livro enquanto objeto e meio, com suas convenções, utilizando-o para construir suas obras, enquanto o colocam, ao mesmo tempo, em xeque.

O fato de muitos artistas focarem seus interesses no livro é um sintoma da força que esse continua tendo, mesmo na era digital, revelando-se elemento bastante enraizado em nossos hábitos, sensações, imaginário, e a própria palavra expandiu-se para compreender tanto o objeto como seu conteúdo. Sem considerar seus conteúdos, todos os textos impressos em um livro se compõem por uma narrativa prevalentemente linear, com um começo e um fim.

A linguagem escrita requer, por sua vez, um material para seu registro, que seja madeira, pedra, papiro, papel ou uma tela, unindo a comunicação a uma entidade física que rejeita o improviso, a mudança ou outros atos performativos, que pertencem à literatura oral e à comunicação ao vivo. O livro condiciona, como apontado por Benjamin, para o uso individualizado, distante nisso da experiência coletiva de uma narração oral. Através do livro, o contato entre autor e leitor acontece no espaço e no tempo, no sentido que todos os livros necessariamente já pertencem ao passado de quando foram escritos, preservando esse passado. Vale destacar também que o livro evita a contingenciada performance oral, em benefício de uma ordem controlada. Mesmo que os livros abram a mente, eles forçam seu conteúdo a acabar, a se fechar, a se deter no tempo: o livro é fixo.

Também do ponto de vista do formato, o livro condicionou as formas através das quais literatura e conhecimento foram concebidos e a maneira como circularam e foram preservados no tempo. Tal modelo tem sido desafiado, pela primeira vez, pela Internet, com seus hipertextos e sua capacidade de facilitar interações comunicativas à distância e em tempo real. São essas novas possibilidades que vêm transformando a abordagem anteriormente "fechada", fixa, da escritura, da leitura, do estudo, da comunicação.

O desafio do livro à comunicação digital não passa somente pela sua persistência, mas também pela criação de suportes digitais que imitam o modelo do livro. Paradoxalmente, o mundo digital acaba imitando o livro. Os artistas selecionados, assim, narram em uma outra linguagem e 
criam livros que não são livros a partir de livros, no sentido que suas obras só existem, dependem de livros. Desconstruindo as narrativas e os livros que as contêm, os artistas avançam na discussão iniciada por Benjamin. Enquanto artistas, o foco deles não é unicamente o de analisar e reproduzir narrativas, mas torná-las materiais, traduzi-las em um artefato que pode ser visto como se lê um livro.

\section{Referências}

BAXANDALL, Michael. Padrões de intenção: a explicação histórica dos quadros. São Paulo: Companhia das Letras, 2006.

BENJAMIN, Walter. Angelus Novus. Torino: Einaudi, 1962.

BORGES, Jorge Luis. Outras inquisições. 1999. Disponível em: https://elivros.info/livro/baixar-outras-inquisicoes-jorge-luis-borges-epub-pdf-mobi-ou-ler-online. Acesso em: 25 jun. 2019.

BORGES, Jorge Luis. O livro de areia. São Paulo: Companhia das Letras, 2009.

CAVALLO, Guglielmo; CHARTIER, Roger. (org.). História da leitura no mundo ocidental. São Paulo: Ática, 2002.

CHARTIER, Roger. (org.). Práticas da leitura. São Paulo: Estação Liberdade, 2001.

CHARTIER, Roger. A aventura do livro: do leitor ao navegador. São Paulo: Unesp, 1999

CURTIUS, Ernst. Literatura europeia e Idade Média latina. São Paulo: Edusp, 1996

DIDI-HUBERMAN, Georges. A imagem sobrevivente: história da arte e tempo dos fantasmas segundo Aby Warburg. Rio de Janeiro: Contraponto, 2013.

FOUCAULT. Michel. Le parole e le cose: unarcheologia delle scienze umane. Milano: BUR, 1988.

FRAISSE, Emmanuel; POMPOUGNAC, Jean-Claude; POULAIN, Martin. Representações e imagens da leitura. São Paulo: Editora Ática, 1997.

GINZBURG, Carlo. Chaves do mistério: Morelli, Freud e Sherlock Holmes. In: ECO, Umberto; SEBEOK, Thomas. (org.). O signo de três. Campinas: Perspectiva, 2004.

GOMBRICH, Ernst. Aby Warburg: una biografia intellettuale. Milano: Feltrinelli, 2003.

MELOT, Michel. L'Illustration: histoire d'um art. Paris: Skira, 1984.

MURRAY, Janet. Hamlet no Holodeck: o futuro da narrativa no ciberespaço. São Paulo: Unesp, 2003.

PANOFSKY, Erwin. Studi di iconologia: i temi umanistici nellarte del Rinascimento. Torino: Einaudi, 1975.

RANCIÈRE, Jacques. The emancipated spectator. Artforum, n. 7, mar. 2007. Disponível em: https://www.artforum.com/print/200703/the-emancipated-spectator-12847. Acesso em: 18 mar. 2020.

SANTAELLA, Lúcia. Navegar no ciberespaço: o perfil cognitivo do leitor imersivo. São Paulo: Paulus, 2004.

SAXL, Fritz. La storia della immagini. Bari: Laterza, 2005.

SCHULTZ, Elisabeth A. Umpainted to the last: Moby Dick and the 20th century American art. Lawrence: University Press of Kansas, 1995.

SETTIS, Salvatore. Warburg Continuatus. In: BARATIN, Marc; JACOB, Christian. (org.). O poder das Bibliotecas: a memória dos livros no Ocidente. Rio de janeiro: UFRJ, 2000.

TESSLER, Elida. Textos críticos. Disponível em: http://www.elidatessler.com/textos_pdf/textos_criticos_1/In\%20 Transition.pdf. Acesso em: 26 jun. 2019.

WARBURG, Aby. L’atlas Mnemosyne. Paris: L'Ecarquillé/INHA, 2012.

Recebido em: 04/07/2019

Aceito em: 17/12/2019 